\title{
An investigation into the participation and attitudes of dental technicians in Wales towards continuing professional development
}

IHE STUDY

The objective of this study was to investigate the participation and attitudes of dental technicians based in Wales towards continuing professional development (CPD). A self-completion postal and online questionnaire was designed and sent to all registered dental technicians in Wales $(n=258)$. The overall response rate was $83(32.1 \%)$; four of the responses were not used due to incomplete answers, leaving 79 for analysis. Just over a quarter of respondents (27.8\%) stated that they find it difficult to keep up-to-date with gaining CPD hours. Lack of time, suitable courses, geographical location and cost were all perceived as significant factors hindering technicians from gaining CPD. The findings highlighted the need for more regional CPD courses in Wales, which could alleviate the geographic barriers. Further research should be considered into the way that courses are delivered, to see if alternative course delivery could alleviate the barriers found in this study.

\section{Introduction}

Continuing professional development (CPD) has evolved over the years and has become an increasingly important feature of most professions. ${ }^{1} \mathrm{CPD}$ varies greatly among professions; however, some degree of consensus has been reached regarding the following definition: 'CPD is the process by which a professional person maintains the quality and relevance of professional services throughout his/her working life.'

The primary role of the General Dental Council (GDC), as a professional body, is to safeguard standards of competence. By regulating the dental team, the GDC aims to protect patients and to promote confidence in dental professionals. ${ }^{2}$ The GDC introduced compulsory CPD to ensure that dentists and dental care professionals (DCPs) are aware of the continuing advancement in dentistry, and to ensure that all registered professionals keep up-to-date with changes in technologies and new approaches to patient care.

A National Health Service (NHS) report stated that CPD programmes need to meet the learning needs of individuals to inspire public confidence and for this reason CPD programmes are best managed locally. ${ }^{3}$ Education consortia and postgraduate deans have a key role to play in developing CPD programmes through working with professional

* Dental Laboratories, Cardiff School of Health Sciences, University of Wales Institute Cardiff; Cardiff, United Kingdom Email: iolahaf@hotmail.com associations to provide the dental team with relevant courses.

It is apparent from relevant literature ${ }^{4-7}$ that there is a wide range of opinions and attitudes to the benefits of CPD, but it has been estimated that the knowledge gained in a degree course has an average useful lifespan of about four years. ${ }^{1}$ This finding highlights the importance of life long learning and the participation in CPD. However, Friedman and Phillips ${ }^{8}$ argue that undertaking compulsory $\mathrm{CPD}$ is merely a 'point gathering exercise.' Gaining verifiable hours and receiving a certificate of attendance does not prove competence, it only indicates presence; although measuring the true level of competence is difficult to achieve through portfolio evidence. . $^{9-10}$

Dental technicians are a relatively small body of professionals, many of whom are selfemployed, working in small laboratories dotted all over the UK. The average laboratory size includes four technicians or fewer ${ }^{11}$ and these low numbers make it harder to evaluate their needs and aspiration towards CPD, particularly when compared to professions such as teachers or nurses which have greater numbers in a given geographical area.

A plethora of research has examined the attitudes and participation in CPD among a number of other professions such as pharmacists, dieticians, nurses and teachers, ${ }^{4,12-14}$ however, there remains a lack of research to identify the barriers inhibiting dental technicians from undertaking CPD. ${ }^{7}$ Prior to compulsory registration, a pilot study was conducted by Reeson and Jepson ${ }^{15}$ involving

\section{'There is a}

wide range of attitudes to the benefits of CPD.'

dental technicians in the North of England to investigate the implications and constraints likely to arise with registration and the introduction of CPD. There was a noticeable difference in the response between commercial and hospital based dental technicians, however, overall the respondents felt that registration 'might' raise the profile status of dental technicians. ${ }^{16}$ It was concluded in the pilot study that further research would be crucial once registration was implemented to examine the impact of the changes, but to date further research has not materialised.

Since compulsory registration for the whole of the dental team was introduced in August 2008, evidence has been limited about dental technicians' participation in CPD. A survey carried out by the Dental Laboratories Association (DLA) on behalf of the GDC during the Grassroots Meetings in September 2009 probed key issues affecting the profession such as registration, $\mathrm{CPD}$, education and the new General Dental Services contract. The general consensus of the respondents $(n=305)$ was that 


\begin{tabular}{|c|c|}
\hline Discriminator (\%) & Number of respondents \\
\hline \multicolumn{2}{|l|}{ Gender } \\
\hline Male & $60(75.9 \%)$ \\
\hline Female & $19(24.1 \%)$ \\
\hline \multicolumn{2}{|l|}{ Years working as a dental technician } \\
\hline Up to 5 & $5(6.3 \%)$ \\
\hline $6-15$ & $10(12.7 \%)$ \\
\hline $16-25$ & $16(20.3 \%)$ \\
\hline $26-35$ & $25(31.6 \%)$ \\
\hline $36+$ & $23(29.1 \%)$ \\
\hline \multicolumn{2}{|l|}{ Current employment } \\
\hline $\begin{array}{l}\text { An owner of a commercial laboratory } \\
\text { with employees }\end{array}$ & $11(13.9 \%)$ \\
\hline $\begin{array}{l}\text { An owner of a commercial laboratory } \\
\text { without employees }\end{array}$ & $15(19 \%)$ \\
\hline A part owner of a commercial laboratory & $4(5.1 \%)$ \\
\hline Employed by a commercial laboratory & $15(19 \%)$ \\
\hline Employed by a NHS hospital laboratory & $27(34.2 \%)$ \\
\hline Employed by an university/college & $6(7.6 \%)$ \\
\hline
\end{tabular}

the ongoing cost of CPD was causing financial problems, while concerns were also raised about the difficulties in gaining CPD due to lack of time. ${ }^{17}$

This paper seeks to investigate the participation and attitudes of dental technicians based in Wales towards CPD, and identify factors affecting participation. Whilst common themes have been raised in previous literature regarding cost and time factors, ${ }^{4,12-14,18}$ another issue which is equally important is the access to relevant courses and the need for more regional events ${ }^{7}$ which provided a pathway for the present study. Friedman et al. ${ }^{18}$ found that access to $\mathrm{CPD}$ activities remains a problem for those not living close to a major city, which could be a problem for dental technicians based in rural Wales. The School of Postgraduate Medical and Dental Education of Cardiff University were keen to investigate the needs of dental technicians in Wales, so that vital change can be implemented before the end of the first CPD cycle if needs be.

\section{Method}

A self-completion postal and online questionnaire was designed ${ }^{19}$ and ethically approved by the Health and Social School
Research Committee at University of Wales Institute, Cardiff. To ensure validity and a group of qualified dental technicians and members of Cardiff University research team. The results of the pilot study were discussed with the research team and minor adjustments were made to the structure of the questionnaire to ensure easy reading for the participants. The questionnaire incorporated both open and closed questions, with one specific question examining attitudes adopting a Likerttype response.

Cardiff School of Postgraduate Medical and Dental Education database was used to identify all registered dental technicians in Wales $(\mathrm{n}=258)$. All were invited to participate in the research. The postal questionnaire was accompanied by a covering letter and a freepost addressed envelope, with the option of replying online using a link to the Bristol Online Survey (BOS) system. Along with the online and free postal options, methods used to encourage response included: advance publicity in CPD meetings run by the Cardiff School of Postgraduate Medical and Dental Education prior to the launch of the questionnaire, and names entered into a draw for early respondents reliability, the questionnaire was piloted with (within ten days of postal date). Due to time constraint, second mailing for non-respondents was not viable.

Postal respondents were inputted into the Bristol Online Survey system and overall results exported to Excel. Analysis was mostly restricted to descriptive statistics, however, where applicable, SPSS (version 17.0) was employed. Specifically, data was pre-screened for statistical assumptions (eg random sampling, independence of observation), before ChiSquare and Spearman's test were performed to examine correlation between two sets of data. $P$ $\leq 0.05$ was considered statistically significant.

\section{RESULTS}

\section{Response rate}

Of the 258 questionnaires that were sent out, 83 ( $32.1 \%$ response rate) were returned. Four of the questionnaires were not used due to incomplete answers, leaving 79 for analysis.

\section{Demographic details}

The demographic details of the 79 respondents are shown in Table 1. There was a significant difference $(P=0.013)$ between the female dental technicians and their current employment. Of the female respondents, $63.2 \%$ were employed by an NHS laboratories compared to only $25 \%$ of the males. Owners/part owners of a commercial laboratory accounted for $10.6 \%$ females and $46.6 \%$ males. Of the respondents, $26.3 \%$ females and $18.3 \%$ males were employed by a commercial laboratories. The remaining male respondents (10.1\%) were employed by universities.

\section{Attitudes towards CPD}

Within the questionnaire, ten of the questions adopted a five point Likert-type scale format, exploring the attitudes of dental technicians towards CPD. The respondents were asked to state to what extent they agreed or disagreed with the statements. The overall response rates are shown in Table 2.

There was a significant correlation $(r=0.468$ $P=0.001$ ) between the statement 'I finance all of my own CPD' and the current employment of dental technicians. From the respondents who owned/part owned a commercial laboratory only $16.6 \%$ disagreed with the statement 'I finance all of my own CPD', 3.3\% were uncertain and the remaining technicians agreed/strongly agreed to the statement. However, it was observed that from the technicians who were employed by a commercial laboratories $31.3 \%$ strongly disagreed with the statement while $68.8 \%$ agreed/strongly agreed. This is a contrast against technicians who are employed by NHS hospitals, $74.1 \%$ strongly disagreed/disagreed to financing all of their own CPD along with 66.7\% 


\begin{tabular}{|c|c|c|c|c|c|}
\hline \multirow[t]{2}{*}{ Statement } & \multicolumn{5}{|c|}{ Number of respondents (\%) } \\
\hline & $\begin{array}{l}\text { Strongly } \\
\text { Disagree }\end{array}$ & Disagree & Uncertain & Agree & Strongly Agree \\
\hline $\begin{array}{l}\text { Introduction of mandatory registration has raised } \\
\text { the profile and status of dental technicians }\end{array}$ & $\begin{array}{l}7 \\
(8.9 \%)\end{array}$ & $\begin{array}{l}16 \\
(20.3 \%)\end{array}$ & $\begin{array}{l}9 \\
(11.0 \%)\end{array}$ & $\begin{array}{l}39 \\
(49.4 \%)\end{array}$ & $\begin{array}{l}8 \\
(10.1 \%)\end{array}$ \\
\hline I welcome mandatory registration & $\begin{array}{l}6 \\
(7.6 \%)\end{array}$ & $\begin{array}{l}10 \\
(12.7 \%)\end{array}$ & $\begin{array}{l}7 \\
(8.9 \%)\end{array}$ & $\begin{array}{l}43 \\
(54.4 \%)\end{array}$ & $\begin{array}{l}13 \\
(16.5 \%)\end{array}$ \\
\hline $\begin{array}{l}\mathrm{CPD} \text { is valuable to a dental technicians } \\
\text { career progression }\end{array}$ & $\begin{array}{l}7 \\
(8.9 \%)\end{array}$ & $\begin{array}{l}5 \\
(6.3 \%)\end{array}$ & $\begin{array}{l}17 \\
(21.5 \%)\end{array}$ & $\begin{array}{l}35 \\
(44.3 \%)\end{array}$ & $\begin{array}{l}15 \\
(19.0 \%)\end{array}$ \\
\hline $\begin{array}{l}\text { Before mandatory CPD was introduced, I kept up to } \\
\text { date with current technology and practice }\end{array}$ & $\begin{array}{l}0 \\
(0.0 \%)\end{array}$ & $\begin{array}{l}5 \\
(6.3 \%)\end{array}$ & $\begin{array}{l}14 \\
(7.7 \%)\end{array}$ & $\begin{array}{l}52 \\
(65.8 \%)\end{array}$ & $\begin{array}{l}8 \\
(10.1 \%)\end{array}$ \\
\hline $\begin{array}{l}\text { I am confident I will achieve the required } 50 \text { hours } \\
\text { verifiable CPD by the end of the five year cycle }\end{array}$ & $\begin{array}{l}2 \\
(2.5 \%)\end{array}$ & $\begin{array}{l}3 \\
(3.8 \%)\end{array}$ & $\begin{array}{l}10 \\
(12.7 \%)\end{array}$ & $\begin{array}{l}37 \\
(46.8 \%)\end{array}$ & $\begin{array}{l}27 \\
(34.2 \%)\end{array}$ \\
\hline $\begin{array}{l}\text { I am confident I will achieve the required } 100 \text { hours } \\
\text { non-verifiable CPD by the end of the five year cycle }\end{array}$ & $\begin{array}{l}2 \\
(2.5 \%)\end{array}$ & $\begin{array}{l}3 \\
(3.8 \%)\end{array}$ & $\begin{array}{l}11 \\
(13.9 \%)\end{array}$ & $\begin{array}{l}35 \\
(44.3 \%)\end{array}$ & $\begin{array}{l}28 \\
(35.4 \%)\end{array}$ \\
\hline To date, I have not undertaken any verifiable CPD & $\begin{array}{l}55 \\
(69.9 \%)\end{array}$ & $\begin{array}{l}19 \\
(24.1 \%)\end{array}$ & $\begin{array}{l}1 \\
(1.3 \%)\end{array}$ & $\begin{array}{l}3 \\
(3.8 \%)\end{array}$ & $\begin{array}{l}1 \\
(1.3 \%)\end{array}$ \\
\hline Gaining CPD contributes to my day to day work & $\begin{array}{l}7 \\
(8.9 \%)\end{array}$ & $\begin{array}{l}13 \\
(16.5 \%)\end{array}$ & $\begin{array}{l}20 \\
(25.3 \%)\end{array}$ & $\begin{array}{l}32 \\
(40.5 \%)\end{array}$ & $\begin{array}{l}7 \\
(8.9 \%)\end{array}$ \\
\hline I finance all of my own CPD & $\begin{array}{l}9 \\
(11.4 \%)\end{array}$ & $\begin{array}{l}25 \\
(31.6 \%)\end{array}$ & $\begin{array}{l}4 \\
(5.1 \%)\end{array}$ & $\begin{array}{l}18 \\
(22.8 \%)\end{array}$ & $\begin{array}{l}23 \\
(29.1 \%)\end{array}$ \\
\hline $\begin{array}{l}\text { Dental technicians who do not meet the General } \\
\text { Dental Council's (GDC) requirements by the end } \\
\text { of the five year CPD cycle should be taken off the } \\
\text { Dental Care Professionals (DCP) register list }\end{array}$ & $\begin{array}{l}10 \\
(12.7 \%)\end{array}$ & $\begin{array}{l}13 \\
(16.5 \%)\end{array}$ & $\begin{array}{l}15 \\
(19.0 \%)\end{array}$ & $\begin{array}{l}20 \\
(25.3 \%)\end{array}$ & $\begin{array}{l}21 \\
(26.6 \%)\end{array}$ \\
\hline
\end{tabular}

of technicians employed by universities.

Opinion varied regarding whether dental technicians should be taken off the DCP register list if they did not comply with the compulsory verifiable and non-verifiable CPD hours. None of the respondents who had been working as a technician for up to five years disagreed with the statement, while the group of technicians who felt most strongly against the statement were technicians who had been working in the profession for $36+$ years.

\section{Barriers in gaining CPD hours}

Just over a quarter of respondents (27.8\%) stated that they find it difficult to keep up-to-date with gaining CPD hours and the barriers affecting them keeping up-to-date are shown in Figure 1. Respondents were asked if geographical location made it difficult for them to participate in verifiable $\mathrm{CPD}$. There was a significant difference $(P=0.015)$ between the respondent's

\section{'Opinion varied}

on whether

technicians

should be taken

off the DCP

register if

they did not

comply with the CPD hours.' geographical location and whether they found it difficult to participate in verifiable CPD. It was apparent, as demonstrated in Figure 2, that technicians based in North Wales and SouthWest Wales find it difficult to gain verifiable CPD due to geographical location. There was no response from technicians based in Mid-Wales.

\section{Discussion}

The purpose of this study was to investigate the participation and attitudes of dental technicians in Wales towards CPD and factors affecting participation. The response rate $(32.1 \%)$ was average for a postal questionnaire, ${ }^{19}$ but it is difficult to give a clear reason for why over half of the technicians did not respond. Reeson and Jepson ${ }^{15}$ experienced the same dilemma with their study involving technicians based in the North of England. It is possible that the nonrespondents had a negative attitude towards $\mathrm{CPD}$ and believe that the study would not 


\section{Fig. 1 Barriers in keeping up-to-date with verifiable CPD}

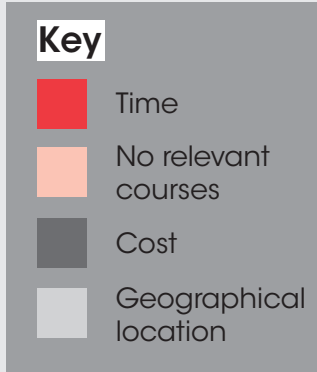

$3,14 \%$

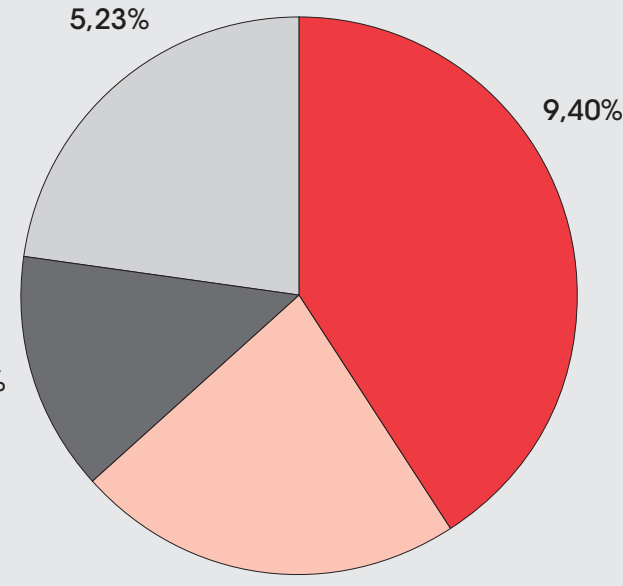

$5,23 \%$

benefit them in any way or just simply that they had no time to complete the questionnaire and did not respond.

Lack of time, no relevant courses, geographical location and cost were all perceived to be a significant factor to hinder technicians from gaining verifiable $\mathrm{CPD}$, which corroborate findings of other studies. ${ }^{12-13,15,17-18}$

Figure 2 highlights the geographical location barriers of those technicians based in North and West Wales. Although the School of Postgraduate Medical and Dental Education have centres all over Wales and try to offer courses on a regular basis, commercial or privately run courses are generally held near a major town/city. Friedman et al. ${ }^{18}$ suggested that activities such as distance learning or e-learning could potentially help to alleviate barriers associated with geographical location. However, bearing in mind that over $60 \%$ of the respondents have worked in the profession for $25+$ years, some individuals may have limited, if any IT experience, so online learning opportunities proposed to alleviate geographical barriers may in itself raise problems if technical support is not offered. Also, dental technology involves superior technical skills, therefore, online courses would lack the 'hands on' aspect that many technicians prefer while undertaking a course..$^{20}$

Cost was least mentioned in the study as a barrier to verifiable CPD, but was still a concern for many technicians, particularly those commercially based. A possible reason for cost being the least mentioned barrier is because the School of Postgraduate Medical and Dental Education of Cardiff University offers courses free of charge or at a minimal cost to all technicians across Wales, not just for NHS/ university staff, so realistically cost of the course should not be an issue. On the other hand, commercial or privately run courses can charge any rate they perceive appropriate, which at times can be very expensive.

A significant correlation between commercially employed technicians and NHS employed technicians was found when asked 'I finance all of my CPD'. This correlation suggests that technicians working in a NHS laboratory are funded more often than not to attend CPD courses. Some commercially based technicians may resent this statement, while employees of commercial laboratories could argue why aren't they funded for in the same way? But it is important to remember that it is the dental technician's own responsibility to ensure that they fulfil the CPD requirements and in reality, it would not be feasible for an employer of a small laboratory to fully fund their employees; therefore it was not surprising that cost was found to be a barrier to CPD in this study.

The School of Postgraduate Medical and Dental Education of Cardiff University was concerned that dental technicians were not participating in CPD courses as much as other DCP groups. However, findings were encouraging in that the respondents felt that they would achieve the required numbers of verifiable and non-verifiable CPD. A positive attitude was also noted towards whether technicians had undertaken any verifiable CPD, specifically, $94 \%$ of the respondents had already undertaken some sort of verifiable CPD to date. It is not clear how many verifiable hours technicians have undertaken, but the findings give us a valuable insight into the positive attitudes that the technicians have in achieving the required verifiable hours within the five year cycle. Currently the GDC states that if a technician fails to meet the required CPD hours, they are at risk of being taken off the DCP register list. In the study, the group who felt most strongly against this statement were technicians who had been working in the profession for $36+$ years. A reason for this could be that technicians close to retirement have less motivation to attend courses, but it is important to remember that as long as they are practising, the inability to learn and develop new skills can impact on patient care.

\section{Conclusion}

All professionals need to adapt to the rapidly changing environment within which they all work, therefore, undertaking CPD is important to keep technical skills and knowledge up-to-date. Despite some negative attitudes, the overall consensus of the respondents welcomed mandatory registration and felt that registration had raised the profile status of dental technicians. Lack of time, no relevant courses, cost and geographical location were all found to be a barrier to gaining verifiable CPD. The findings also highlighted the need for more regional CPD courses in Wales, which could alleviate the geographic barriers.

Currently course providers have to meet the requirement of the GDC and evaluate the verifiable CPD programmes delivered. Further research should be considered into the way that courses are delivered, to see if alternative course delivery could alleviate the barriers found in this study.

The author is grateful for the support received by the School of Postgraduate Medical and Dental Education of Cardiff University.

1. Kennie T J M. The growing importance of CPD. Continuing Professional Development 1998; 1: 156-167.

2. General Dental Council. Standards for dental professionals. London: GDC, 2005.

3. Continuing Professional Development: quality in the new NHS. Department of Health, 1999.

4. Power A, Johnson J, Diack L et al. Scottish pharmacists' views and attitudes towards continuing professional development. Pharm World Sci 2008; 30: 136-143.

5. O'Sullivan J. Continuing professional development - is it beneficial? Physiotherapy 2004; 90: 174-175.

6. Leggate M, Russell E. Attitudes and trends of primary care dentists to continuing professional development: a report from the Scottish dental practitioners survey 2000. $\mathrm{Br}$ Dent J 2002; 193: 465-469.

7. Mottram D R, Rowe P, Gangani N, Al-Khamis Y. Pharmacists' engagement in continuing education and attitudes towards continuing professional development. Pharm J 2002; 269: 618-622.

8. Friedman A, Phillips M. Leaping the CPD hurdle: a study of the barriers and drivers 


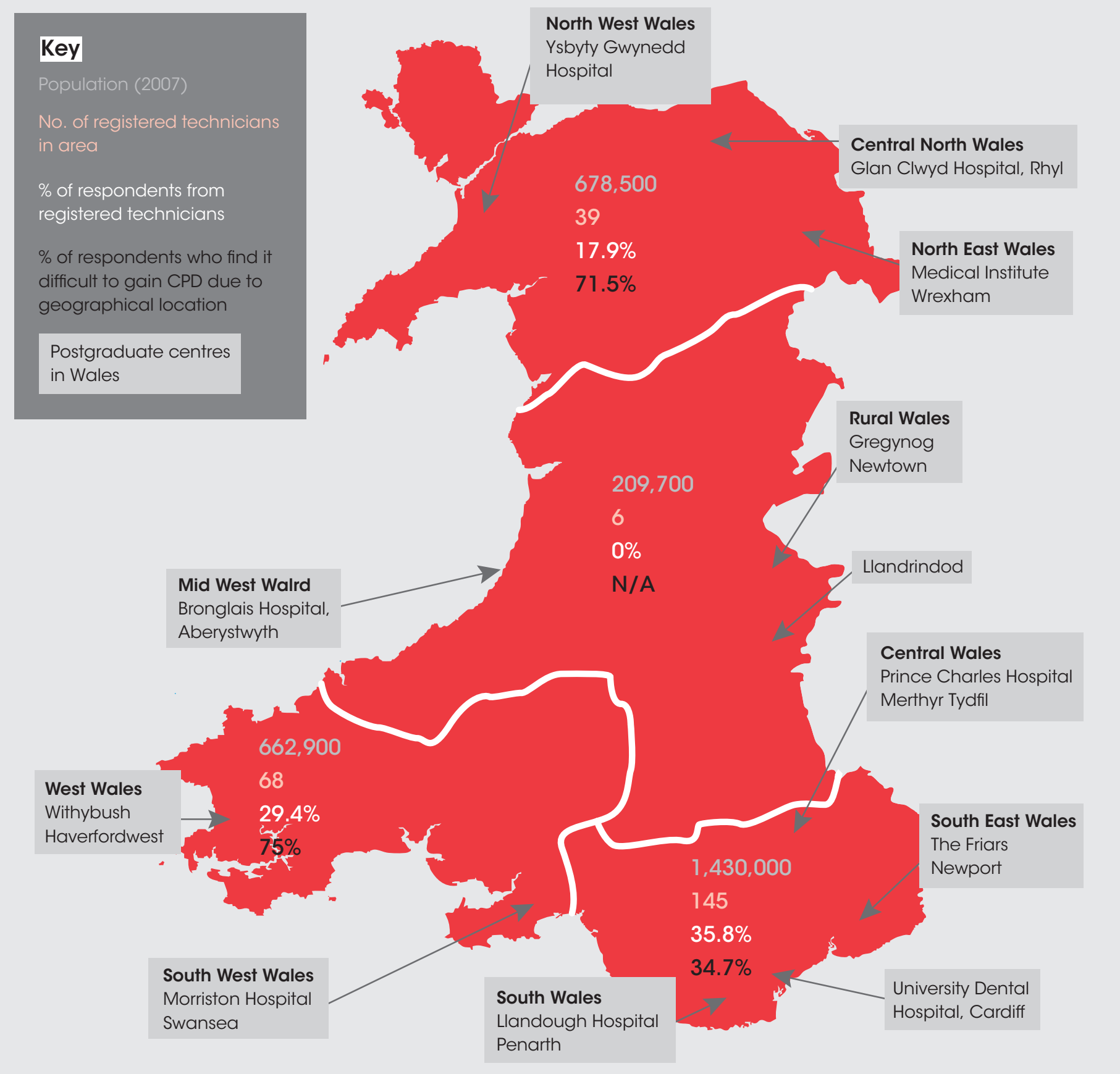

to participation in continuing professional development. University of Bristol: PARN, 2001.

9. Friedman A, Phillips M. Continuing professional development: developing a vision. J Educ Work 2004; 17: 361-376.

10. Eraut M. Developing professional knowledge and competence, $2^{\text {nd }}$ ed. London: Falmer Press, 2003.

11. UK dental laboratory industry survey report 2001/2002. London: LCS International Consulting Ltd, 2002.

12. Sturrock J B E, Lennie S C. Compulsory continuing professional development: a questionnaire-based survey of the UK dietetic profession. J Hum Nutr Diet 2009;
12: $12-20$.

13. Gould D, Drey N, Berridge E. Nurses' experience of continuing professional development. Nurse Educ Today 2007; 27: 602-609.

14. CPD teaching survey commissioned by Wellcome Trust. Available from: http://www. wellcome.ac.uk/About-us/Publications/ Reports/Education/Believers-Seekersand-Sceptics/WTD022231.htm (accessed 11/11/2009).

15. Reeson M G, Jepson N A. Professional development for dental technicians; a pilot study. Br Dent J 2007; 202: 685-689.

16. Stiven A. Grassroots day reveals mainly negative consensus. Dent Tech 2009; 62: 1-4.
17. Bower E J, Newton P D, Gibbons D E, Newton J T. A national survey of dental technicians: career development, professional status and job satisfaction. Br Dent J 2004; 197: 144-148.

18. Friedman A, Davis K, Phillips M. Continuing professional development in the UK: attitudes and experiences of practitioners. Bristol: PARN, 2001.

19. Oppenheim A N. Questionnaire design, interviewing and attitude measurement. London: Continuum, 2005.

20. South Yorkshire \& East Midlands Postgraduate Dental Education Office. Continuing professional development (CPD) survey. Dental Lab J 2007; 32: 42-45. 